\title{
Study of dendrophthoe pentandra ethyl acetate extract as potential anticancer candidate on safety and toxicity aspects
}

\begin{abstract}
In the present study, the safety and toxicity of Dendrophthoe pentandra (DP) extracted using ethyl acetate were investigated. DP ethyl acetate (DPEA) extract was screened for its phytochemical constituents using standard procedure and active compounds present in DPEA extract were determined using gas chromatography-mass spectrometry (GCMS), the toxicity of DPEA extract was investigated using brine shrimp lethality assay (BSLA) while the heavy metal content of DP plant was detected using atomic absorption spectrophotometer (AAS) and the cytotoxicity effect of DPEA extract on selected cell lines (HeLa, L929, Glioma, MD-AMB 231, Hep G2 and MCF-7) was determined through MTT assay. The results showed that DPEA extract consist of wide range of bioactive compounds including tannins, saponins, flavonoids and alkaloids. The crude extract contained $1.33 \%$ alkaloid, $2.67 \%$ flavonoid and $14.87 \pm 0.2 \mu \mathrm{g} / \mathrm{g}$ total phenolic content. Heavy metals such as copper, zinc and manganese were present below the maximum permissible level. GC-MS result revealed the presence of 39 compounds and out of that, only decanoic acid, palmitic acid, linolenic acid and beta-sitosterol were suggested to contribute to the medicinal use of DP. The $\mathrm{LC}_{50}$ of DPEA extract was underdetermined and was predicted above 1000 ppm and DPEA extract showed antiproliferative activity on MCF-7 and L929 with LC of $4.72 \pm 0.52 \mu \mathrm{g} / \mathrm{ml}$ and $18.12 \pm 3.46 \mu \mathrm{g} / \mathrm{ml}$ respectively. Thus, the result of the present study revealed that DP plant is relatively safe and can be considered as possible candidates with promising potency to be developed as new chemotherapeutic agent.
\end{abstract}

Keywords: dendrophthoe pentandra, bioactive compounds, bsla, heavy metals, $\mathrm{lc}_{50}, \mathrm{lc}_{50}$
Volume 6 Issue I - 2017

\section{Lau Shin Yee, Nurul Fatihah Mohd Fauzi, Nik Nurul Najihah, Nik Mat Daud, Mohd Dasuki Sulain}

Department of Biomedicine, School of Health Science, University of Science Malaysia

\begin{abstract}
Correspondence: Mohd Dasuki Sul'ain, Department of Biomedicine, School of Health Science, University of Science Malaysia, Health Campus, Kubang Kerian, 15200 Kubang Kerian, Kelantan, Malaysia,Tel +609767758I, Email drdasuki@usm.my
\end{abstract}

Received: July 23, 2017 | Published: September 13, 2017
Abbreviations: DP, dendrophthoe pentandra; DPEA, DP ethyl acetate; GC-MS, gas chromatography-mass spectrometry; BSLA, brine shrimp lethality assay; AAS, absorption spectrophotometer; FDA, food and drug administration; EFSA, European food safety authority; CLA, linolenic acid; GACP, good agricultural and collection practices; GMP, good manufacturing practices

\section{Introduction}

From the dawn of ancient medicine, herbal medicine has become a topic of global importance, making an impact on both world health and international trade over the past 30 years for their potential as novel cancer preventive and therapeutic agents. ${ }^{1,2}$ Medicinal plants continue to play a central role in the healthcare system of large proportions of the world's population. Approximately $60 \%$ of drugs currently used for cancer treatment have been isolated from natural products and the plant kingdom has been the most significant source. ${ }^{3}$ Many traditional healers and herbalists have been treating cancer patients for many years using various medicinal plant species. ${ }^{1}$

Dendrophthoe pentandra (DP) or mistletoe is an evergreen semiparasitic shrub from the Viscaceae (Loranthaceae) family with various types which can grow on the branches of various deciduous trees including tea, apple, pine, mango, lime, larch, pear, oak and some other plants. Approximately, 1500 species of mistletoe have been found worldwide. ${ }^{4}$ Different species of mistletoe can grow on the same host plant or the other way round where one species of mistletoe grow on multiple host trees. ${ }^{5,6}$ Since mistletoe is a semiparasitic epiphyte, it is suggested that their bioactivities could also depend on their host plant.

Mistletoe contains different types of biological active compounds such as carbohydrates, fats, amino acids, oligosaccharides, polysaccharides, enzyme, flavonoid, glycoprotein (lectin MLT), polypeptide (viscotoxin), vesicles, and triterpene acids. The chemical composition of mistletoe varies depending on the techniques of extract preparation, season and time of harvesting, commercial producer, stage of growth of the plant, location, and species of host tree. Lectins (MLI, ML-II, and ML-III) are the main constituents of mistletoe which are responsible for its anticancer and immunomodulatory effects. Researchers are looking forward for the use of medicinal plants in combination with conventional medicine as supportive therapy to improve health-related quality of life. ${ }^{4}$ As an anthroposophical medicine, mistletoe considered as one of the most important herbal medicine and has the potential to be used in the treatment of cancer. Founder of anthroposophy medical method, Rudolf Steiner has introduced mistletoe into oncology in 1920 and it has been used as an unconventional method in cancer therapy. Marvibaigi et al. ${ }^{4}$ stated that, using mistletoe extract in cancer therapy especially breast cancer is recommended due to its minimal side effects and the fact that these side effects are not life threatening.

In Malaysia, Drug Control Authority (DCA) had emphasis on the quality efficacy and safety of all pharmaceutical dosage forms of traditional medicine preparations. DCA has set registration criteria on traditional medicine particularly on the limits for heavy metals, limits for microbial contaminations and the absence of steroids and other adulterants, limits of disintegration time, claimed indications, prohibition of herbs with known adverse effects, prohibition of endangered animal species and compliance to good manufacturing practice. Therefore, the aims of this work are to evaluate the safety and toxicity of ethyl acetate extract of Dendrophthoe pentandra (DPEA) as potential anticancer agent. This work also screen the phytochemical constituents of DPEA extract and determine the active compounds present in DPEA extract through gas chromatographymass spectrometry (GC-MS). 


\section{Materials and methods}

\section{Plant material}

The leaves of Dendrophthoe pentandra (DP) were collected at Pasir Hor, Kelantan from Lansium parasiticum tree in May 2013 and aunthenticated by a botanist of Herbarium Unit, School of Biological Sciences, Universiti Sains Malaysia, Penang, Malaysia. A voucher herbarium specimen was deposited at the Department's herbarium (Voucher No. 11289). The leaves were washed, dried and blended into powdered form. The plant powder was stocked in refrigerators at $-20 \circ \mathrm{C}$.

\section{Extraction of dendrophthoe pentandra}

Successive solvent extractions were performed in ascending order of petroleum ether, diethyl ether, chloroform and lastly ethyl acetate (Merck, Malaysia). Petroleum ether extract was prepared by soaking powdered sample with petroleum ether in a ratio of 1:10 and placed on a shaker overnight at room temperature. The extract was filtered and concentrated using rotary evaporator (Rotavac Heidolph Laborate 4000 series) with water bath set at $25 \mathrm{oC}$, followed by evaporating in fume hood for several days. The dried residue was further extracted with the following organic solvent sequence of diethyl ether, chloroform, and finally ethyl acetate. The same procedure was repeated to give diethyl ether extract. The same residue remained was re-used for the subsequent extract by reflux method. Later on, the ethyl acetate extract was dissolved in dimethylsulfoxide (DMSO) to form stock solution of $10 \mathrm{mg} / \mathrm{mL}$. The yields of extracts were calculated using the following formula:

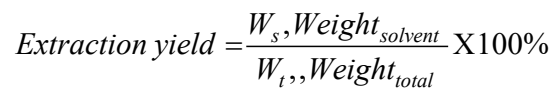

Where,

$\mathrm{W}_{\mathrm{s}}=$ Weight of the extract in respective solvent.

$\mathrm{W}_{\mathrm{t}}=$ Total weight of the DP plant extract of all solvent.

\section{Phytochemical class of dendrophthoe pentandra}

Dendrophthoe pentandra ethyl acetate (DPEA) extract was preliminary screened qualitatively and quantitatively for phytochemical constituents according to the protocols described by Sofowara $^{7}$ and Harborne. ${ }^{8}$

\section{Qualitative phytochemical screening}

Detection of flavonoids: $1 \mathrm{~mL}$ plant extract was added to $1 \mathrm{~mL}$ of $10 \%$ lead acetate and gently shaken. A muddy brownish precipitate indicates the presence of flavonoids.

Detection of tannins: $1 \mathrm{~mL}$ of plant extract was added to $1 \mathrm{~mL}$ of $3 \%$ iron (III) chloride. A greenish black precipitate signifies the presence of tannins.

Detection of alkaloids: $1 \mathrm{~mL}$ of plant extract was stirred with $5 \mathrm{~mL}$ $(1 \%)$ hydrochloric acid on a steam bath $(60 \mathrm{oC})$ for $15 \mathrm{~min}$ and filtered. $1 \mathrm{~mL}$ of Dragendorff reagent was added to $1 \mathrm{~mL}$ filtrate. The formation of cloudy orange is formed indicate the presence of alkaloids.

Detection of terpenoids: $5 \mathrm{~mL}$ extract was mixed with $2 \mathrm{~mL}$ chloroform. Then $3 \mathrm{~mL}$ concentrated sulphuric acid was carefully added to observe a reddish brown coloration between upper and lower layer. Formation of reddish brown coloration between those layers signifies the presence of terpenoids.
Detection of saponins: Approximately $0.2 \mathrm{~mL}$ extract was mixed with $5 \mathrm{~mL}$ distilled water and was shaken vigorously for $5 \mathrm{~min}$. Persistence of foams was the indicator for saponins.

\section{Quantitative phytochemical screening}

Total alkaloids: DP extract was dispered in 10\% acetic acid solution in ethanol in a ratio of 1:10. The mixture were allowed to stand for 4 hours at $28^{\circ} \mathrm{C}$. Subsequently, it was filtered and the filtrate was concentrated to one quarter of its original volume by evaporation and treated with drop wise addition of concentrated aqueous ammonium hydroxide solution $\left(\mathrm{NH}_{4} \mathrm{OH}\right)$ until the alkaloid will precipitated. The alkaloid precipitated was received in a weighed filter paper, washed with $1 \%$ ammonia solution dried in the oven at $80^{\circ} \mathrm{C}$. Alkaloid contents was calculated and expressed as a percentage of the weight of sample anlyzed.

Total flavonoid: $5 \mathrm{~g}$ of DP extract was boiled in $50 \mathrm{~mL}$ of $2 \mathrm{M} \mathrm{HCl}$ solution for $30 \mathrm{~min}$ under reflux. It was allowed to cool and then filtered. A measured volume of the extract was treated with equal volume of ethyl acetate starting with a drop. The flavonoid precipitated was recovered by filtration using weighed filter paper. The resulting weight difference gave the weight of flavonoid in the sample.

Total phenolic content (TPC): 100g of DPEA extract was dissolved in $1 \mathrm{~mL}$ of $1 \%$ hydrochloric acid in methanol $(\mathrm{v} / \mathrm{v})$. The extract was then centrifuged at 6000rpm for 60mins (Hettich Zentrifugen; Universal $32 \mathrm{R}) .100 \mu \mathrm{l}$ of supernatant was pipetted into a bottle after which $750 \mu 1$ of Folin-Ciocalteau reagent (10 x dilutions) was added. The solution was left to stand at room temperature $(25 \mathrm{oC})$ for 5 minutes. After that, $750 \mu \mathrm{l}$ of sodium bicarbonate $(60 \mathrm{mg} / \mathrm{mL})$ was mixed into the solution and left to react in the dark for 90minutes. Distilled water was used as a blank in the analysis. The absorbance of the sample was read at $725 \mathrm{~nm}$ by using UV-VIS spectrophotometer (Varians, USA). The TPC was calculated by comparing the absorbance with the tannic acid calibration curve according to the following formula:

Where,

$$
T P C(\mu g / g)=C X \frac{V}{g}
$$

$\mathrm{C}=$ concentration of the tannic acid equivalent from standard curve $(\mu \mathrm{g} / \mathrm{mL})$.

$\mathrm{V}=$ volume of the extract used $(\mathrm{mL})$ and $\mathrm{g}=$ weight of extract $(\mathrm{g})$

The contents were expressed as tannic acid equivalent ( $\mu \mathrm{g}$ TAE/g).

\section{Chemical compounds identification of dendrophthoe pentandra using GC-MS}

$50 \mu \mathrm{g}$ of crude plant extract was dissolved in $2 \mathrm{~mL}$ methanol and put into GC-MS vial for GC-MS analysis. GC-MS analysis was carried out on a GC Agilent Technologies 6890 Network System and gas chromatography interfaced to a mass spectrometer Agilent Technologies 5973 inert Mass Selective Detector. For identification of components, the interpretation on mass spectrum GC-MS was conducted using database of National Institute Standard and Technologies (NIST) 2002 having more than 62000 patterns. The spectrum of the unknown component was compared with the spectrum of the known components in the NIST library. The name, molecular weight and molecular structure of the components of the test material were ascertained.

\section{Estimation of lethal dose (LC50) of Dendrophthoe pentandra using brine shrimp lethality assay (BSLA)}

$0.25 \mathrm{~g}$ of brine shrimp eggs (nauplii) were hatched in a well aerated 
beaker containing $3.8 \%$ of $250 \mathrm{~mL}$ seawater (sea salt in distilled water). Then, it is left at room temperature for 24 to 48 hours with bright light for the hatching process. Later, $0.2 \mathrm{~g}$ of DPEA extract was dissolved in $100 \mathrm{~mL}$ of distilled water to make $2000 \mathrm{ppm}$ concentration of stock solution. Serial dilution will be carried out using the stock solution to prepare working extract solution with $1000 \mathrm{ppm}, 500 \mathrm{ppm}, 250 \mathrm{ppm}$, $125 \mathrm{ppm}, 62.5 \mathrm{ppm}, 31.2 \mathrm{ppm}, 15.6 \mathrm{ppm}$ and $7.8 \mathrm{ppm}$ concentration. After the hatching process completed, $5 \mathrm{~mL}$ of each extract solution and $5 \mathrm{ml}$ of seawater containing 10 brine shrimp eggs were treated and incubated in petri dish. The petri dishes were left for 24 hour at room temperature with well aerated condition and bright light source. Each of the petri dish was examined after 24hours by using magnifying glass and the average number of survived nauplii was counted. The control for this assay is $10 \mathrm{~mL}$ of seawater containing 10 brine shrimp eggs. The percentage (\%) of mortality of the brine shrimp nauplii was calculated using the following formula:

$\%$ Mortality $=\mathrm{Nt} / \mathrm{No}$ X100

Where,

$\mathrm{Nt}=$ number of killed nauplii after 24 hours of incubation.

$\mathrm{No}=$ number of total nauplii transferred, that is 30 .

\section{Elemental analysis of dendrophthoe pentandra using AAS}

$0.5 \mathrm{~g}$ of DPEA extract was subjected to dry ash in well cleaned porcelain crucible at $550^{\circ} \mathrm{C}$ in a muffle furnace. The resultant ash was dissolved in $5 \mathrm{~mL}$ nitric acid/hydrogen peroxide $(\mathrm{HNO} / \mathrm{HO})(1: 1)$ and heated gently on hot plate until brown fumes disappeared. $5 \mathrm{~mL}$ of distilled water was added and heated until colourless solution was obtained. The digested sample were then diluted to $100 \mathrm{~mL}$ distilled water and filtered. This solution was used for elemental analysis by AAS (PerkinElmer, Model Aanalyst 800).

\section{Cytotoxicity test of dendrophthoe pentandra using MTT assay}

Cells were seeded 24 hours prior to treatment in a 96-well plate with a density of $5 \times 10^{4}$ cells/well in $100 \mu \mathrm{L}$ of medium in order to obtain $70 \%-80 \%$ confluent cultures within 24 hours. Then, the medium was discarded and the cells were supplied with $200 \mu \mathrm{L}$ growth medium. DPEA extract was dissolved in DMSO, followed by a 2 times serial dilution from 0.2 to $100 \mu \mathrm{g} / \mathrm{mL}$ was added to the cells in $200 \mu \mathrm{L}$ medium. The 96-well plate was incubated for 72 hours at $37 \mathrm{oC}$ in a humidified atmosphere with $5 \% \mathrm{CO}_{2}$. At the end of incubation, $50 \mu \mathrm{L}$ of MTT solution ( $2 \mathrm{mg} / \mathrm{mL}$ MTT in plain culture medium) was added to each well and incubated for 4hours. MTT solution was removed and the purple formazan crystal formed at the bottom of the wells was dissolved with $200 \mu \mathrm{L}$ DMSO for 30 minutes. The absorbance at $570 \mathrm{~nm}$ was read on a spectrophotometric microplate reader. The proportion of surviving cells was calculated as follow:

$\%$ Cell Viability $=$ (Absorbance of extract) (Absorbance of negative control) X 100

Dose response curve was constructed to determine the $\mathrm{IC}_{50}$ values.

\section{Statistical analysis}

All experiments will be run in triplicate. Data will be subjected to analysis of varience (ANOVA) and mean comparisons will be carried out by using Duncan's multiple range tests. Statistical analysis will be performed using the Statistical Package for Social Sciences (SPSS for windows: SPSS Inc. Chicago, II., USA, 2006).

\section{Results}

\section{Yield of dendrophthoe pentandra from different solvent extraction}

The weight of each solvent extract was recorded and presented in the form of percentage in Figure 1.

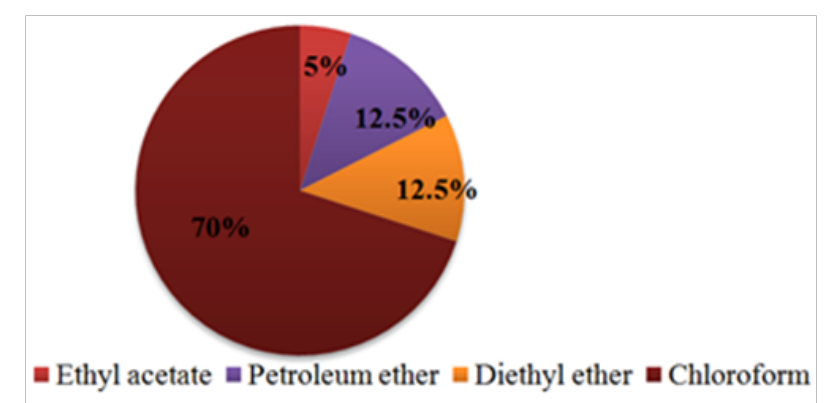

Figure I Percentage yield of DP extracts using solvent extraction.

\section{Phytochemical screening of dendrophthoe pentandra ethyl acetate extract}

The qualitative phytochemical screening of DPEA extract shows that DP comprises of tannins, saponins, flavonoids and alkaloids but without terpenoids. The results were summarized in Table 1. The quantitative phytochemical analysis of DPEA extract shows the presence of $1.3 \pm 0.2 \%$ of alkaloid, $2.7 \pm 0.1 \%$ of flavonoid and $14.9 \pm 0.2 \mu \mathrm{g} / \mathrm{g}$ of total phenolic content using tannic acid equivalent. The findings were summarized in Table 2.

Table I Phytochemical screening from DP leaves extract

\begin{tabular}{ll}
\hline Constituent & Ethyl Acetate (Solvent) \\
Tannins & + \\
Saponins & + \\
Flavonoids & + \\
Terpenoids & - \\
Alkaloids & +
\end{tabular}

Key: + indicate the presence of constituent.

- indicate the absence of constituent.

Table 2 Quantitative phytochemical identification of DPEA extract

\begin{tabular}{ll}
\hline Phytochemical Class & Value \\
\hline Alkaloid & $1.3^{\mathrm{a}} \pm 0.1 \%$ \\
Flavonoid & $2.7^{\mathrm{b}} \pm 0.1 \%$ \\
Total phenolic content & $14.9^{\mathrm{c}} \pm 0.1 \mu \mathrm{g} / \mathrm{g} \mathrm{TAE}$ \\
\hline
\end{tabular}

Values represent means \pm standard deviation.

These assays were done in triplicate $(p<0.05)$.

\section{GC-MS analysis of dendrophthoe pentandra ethyl acetate extract}

The active principles with their retention time (RT), peak area in percentage, and name of the compound were presented in Table 3 . The GC-MS analysis revealed that 39 compounds were detected from the crude DPEA sample (Figure 2). Out of these 39 compounds, the most highly abundance compounds of higher peak area such as, acetoacetic acid, citramalic acid, linolenic acid, ethylene glycol, monoacetate, and beta-sitosterin were highlighted and listed as follow. 


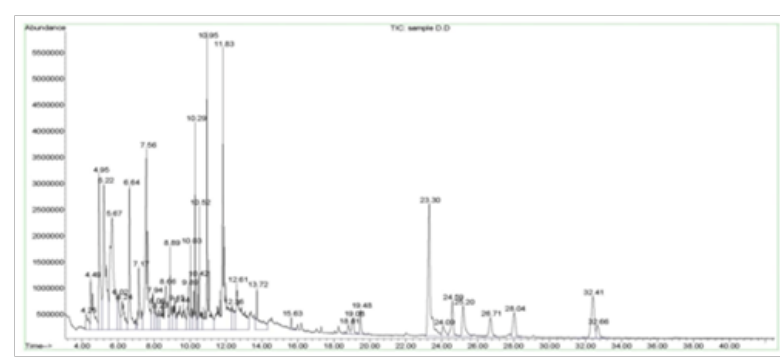

Figure 2 GC-MS chromatogram on DPEA extracts.

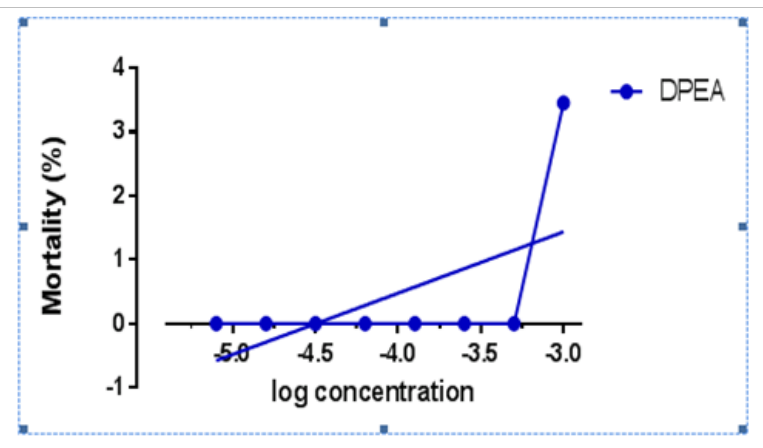

Figure 3 The relationship between the mortality rate and log different concentration of the DPEA extracts.

\section{Brine shrimp lethality assay (BSLA)}

The lethality of the DPEA extract to brine shrimp was determined and the values were expressed in Table 4. The mortality of brine shrimp increased with increasing concentration for DPEA extract. It shows that effect of DPEA was concentration dependent on brine shrimp nauplii. Using BSLA, DPEA extract had shown the mortality rate of only $3.45 \%$ at the highest concentration of $1000 \mathrm{ppm}$ whereas no mortality been observed at other lower concentrations. The mean results of brine shrimp mortality against the logarithms of concentrations were plotted in Figure 3 using the GraphPad Prism version 6.01 program and the regression equations were used to calculate $\mathrm{LC}_{50}$ value.
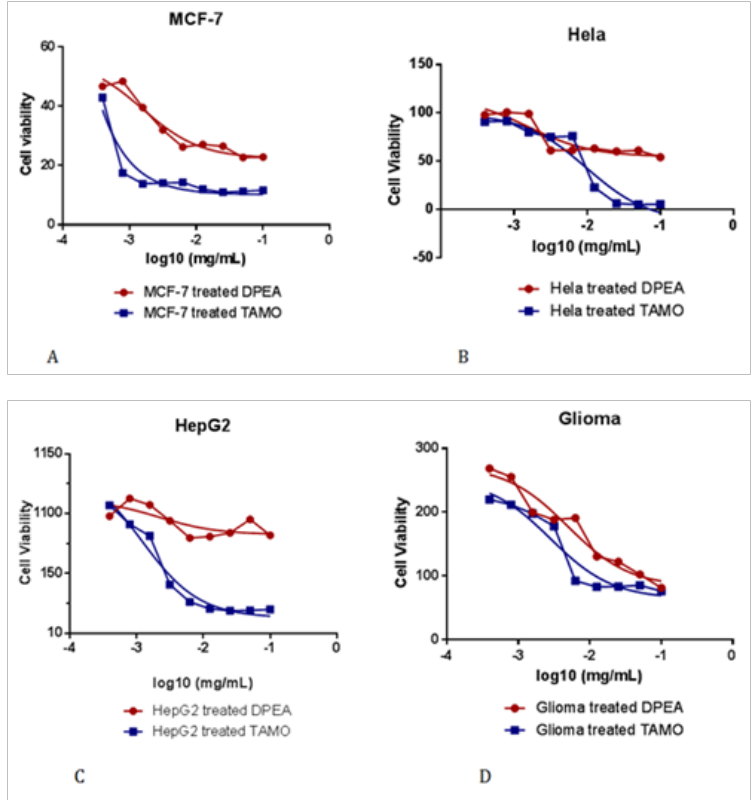
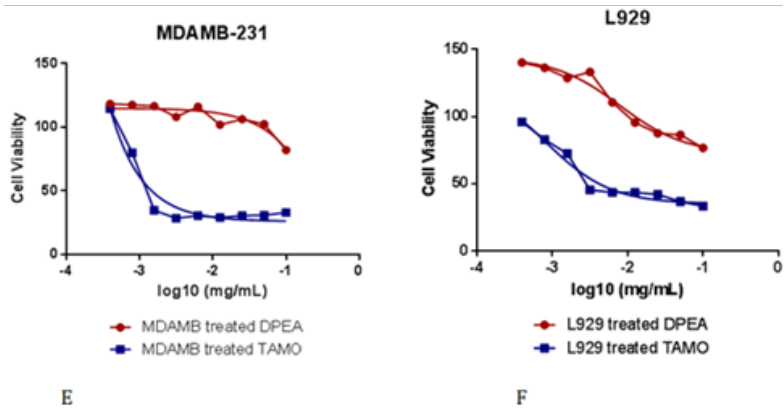

Figure 4 Relationship between the percentage of cell viability and logarithms of different concentration of DPEA extract with representative cell line.

\section{Heavy metal level in dendrophthoe pentandra}

The elemental composition of lead, cadmium and chromium were not detected in DPEA whereas copper, zinc and manganese were detected with respective value as shown in Table 5.

\section{Cytotoxicity analysis of dendrophthoe pentandra etht acetate extract}

To further confirm cytotoxicity of DPEA extract, the extract was screened by MTT assay for cytotoxicity effect against MCF-7, HeLa, Hep G2, glioma, MDA-MB-231, and normal mammalian (L929) cell lines (Table 6). The graphs on relationship between the percentage of cell viability and logarithms of different concentration of DPEA extract with representative cell lines were shown in Figure 4.

\section{Discussion}

Cancer is often associated with increased risk of death and patients often suffered from the toxic side effects caused by the modern medicine. Therefore a lot of cancer patients seek for alternative and complementary methods of treatment such as usage of phytomedicine. ${ }^{9}$ On the other hand, WHO has emphasized strongly on the rational use of traditional and natural indigenous medicines, for treating diseases. ${ }^{10}$ In this regard, we had conducted several studies to determine the safety and toxicity as well as phytochemical constituents and active compounds of medicinal plant, Dendrophthoe pentandra which is the potential anticancer agent.

Phytochemicals are chemical compounds that naturally occur in plants and responsible for color and other organoleptic properties and may have some biological significance like carotenoids and flavonoids but not established as essential nutrients. ${ }^{11-13}$ Phytochemistry or plant chemistry had developed in recent years as distinct discipline and pointed out by Harbone ${ }^{8}$ that natural product organic chemistry and plant biochemistry is closely related to both. It is concerned with the enormous variety of organic substances that are elaborated and accumulated by plants and deals with the chemical structures of these substances, their biosynthesis, turnover and metabolism, their natural distribution and their biological function. ${ }^{8}$ In the experiment, methods are needed for separation and identification of the many different constituents present in plants.

In the present study DP leaves was found out to be rich in tannins, saponins, flavonoids and alkaloids while terpenoids were absent. Tannins are defines as phenolic compounds of high molecular weight ranging from $500 \mathrm{Da}$ to $3000 \mathrm{Da}$. It is closely associated with plant defense mechanisms and have beneficial effects on protein metabolism in ruminants, decreasing rumen degradation of dietary protein and increasing absorption of amino acids in the small intestine. ${ }^{14}$ Although 
tannins have astringency ${ }^{15}$ and poor bioavailability ${ }^{16}$ it is reported to possess the ability to reduce the risk of cardiovascular disease, ${ }^{17,18}$ antioxidant activity and anti-carcinogenic as well as anti-mutagenic properties. ${ }^{19}$ The present study was in agreement with the findings of researchers which reported that the DP leaves have high antioxidant activities. ${ }^{6,20}$ These perhaps, explain why DP is used in treating wounds and skin infection due to the presence of tannins that hasten the healing of wounds and inflamed mucous membrane. ${ }^{21}$

Table 3 Library search report of GC/MS chromatogram revealing bioactivecomponents in DPEA extract

\begin{tabular}{|c|c|c|c|c|c|}
\hline \multirow[t]{2}{*}{ No } & RT & Peak Area & Library ID & Molecular Weight (g/mol) & Molecular Formula \\
\hline & & & 1,3,6-Trioxocane, 2-methyl- & 132.16 & $\mathrm{C}_{6} \mathrm{H}_{12} \mathrm{O}_{3}$ \\
\hline \multirow[t]{3}{*}{ I } & 5.22 & 7.07 & Butanoic acid, 2,2-dimethyl-3-oxo-, methyl ester & 144.17 & $\mathrm{C}_{7} \mathrm{H}_{12} \mathrm{O}_{3}$ \\
\hline & & & N,N-Dimethyl-3-tert-butoxypropylamine & 159.26 & $\underline{\mathrm{C}}_{9} \underline{\mathrm{H}}_{21} \mathrm{NO}$ \\
\hline & & & Butanedioic acid, 2-hydroxy-2-methyl-, (S)- & 148.11 & $\mathrm{C}_{5} \mathrm{H}_{\underline{8}} \mathrm{O}_{5}$ \\
\hline \multirow[t]{2}{*}{2} & 5.67 & 8.92 & I,2-Ethanediol, monoacetate & 104.10 & $\mathrm{C}_{4} \mathrm{H}_{8} \mathrm{O}_{3}$ \\
\hline & & & Pentanoic acid, 3-hydroxy-, methyl ester & 146.18 & $\mathrm{C}_{7} \mathrm{H}_{14} \mathrm{O}_{3}$ \\
\hline \multirow[t]{2}{*}{3} & 7.57 & 8.10 & n-Decanoic acid & 172.26 & $\mathrm{C}_{10} \mathrm{H}_{20} \mathrm{O}_{2}$ \\
\hline & & & $9,12,15-$ Octadecatrienoic acid, $(\mathrm{Z}, \mathrm{Z}, \mathrm{Z})-$ & 278.43 & $\mathrm{C}_{18} \mathrm{H}_{30} \mathrm{O}_{2}$ \\
\hline \multirow[t]{2}{*}{4} & 11.83 & 9.55 & $9,12,15$-Octadecatrien-I-ol, (Z,Z,Z)- & 264.45 & $\mathrm{C}_{18} \mathrm{H}_{32} \mathrm{O}$ \\
\hline & & & $9,12,15-$ Octadecatrienoic acid, ethyl ester, (z, z, z)- & 306.48 & $\mathrm{C}_{20} \mathrm{H}_{34} \mathrm{O}_{2}$ \\
\hline 5 & 23.31 & 6.45 & $\begin{array}{l}\text { Stigmasterol, 22,23-dihydro- } \\
\text { gamma. -Sitosterol beta. -Sitosterin }\end{array}$ & 414.72 & $\mathrm{C}_{29} \mathrm{H}_{50} \mathrm{O}$ \\
\hline
\end{tabular}

Table 4 Number of shrimp nauplii that survived after treating with DPEA extract and mortality rate

\begin{tabular}{|c|c|c|c|c|c|c|}
\hline \multirow{2}{*}{ Plant Extract DP } & \multirow{2}{*}{ Concentration (ppm) } & \multicolumn{3}{|c|}{ Number of Surviving (after 24 hours) } & \multirow{2}{*}{\multicolumn{2}{|c|}{ Total Number of Survivors \% Mortality }} \\
\hline & & RI & $\mathbf{R 2}$ & R3 & & \\
\hline \multirow{8}{*}{$\begin{array}{l}\text { Ethyl } \\
\text { Acetate } \\
\text { Extract }\end{array}$} & 1000 & 9 & 10 & 10 & 29 & 3.45 \\
\hline & 500 & 10 & 10 & 10 & 30 & 0 \\
\hline & 250 & 10 & 10 & 10 & 30 & 0 \\
\hline & 125 & 10 & 10 & 10 & 30 & 0 \\
\hline & 62.5 & 10 & 10 & 10 & 30 & 0 \\
\hline & 31.5 & 10 & 10 & 10 & 30 & 0 \\
\hline & 15.6 & 10 & 10 & 10 & 30 & 0 \\
\hline & 7.8 & 10 & 10 & 10 & 30 & 0 \\
\hline
\end{tabular}

Table 5 Elemental composition of DP leaves using AAS

\begin{tabular}{ll}
\hline Elemental Analysis & Value Detected \\
\hline Copper & $3.0^{\mathrm{a}} \pm 0.1 \mathrm{ppm}$ \\
Zinc & $1.1^{\mathrm{b}} \pm 0.1 \mathrm{ppm}$ \\
Lead & $0.0^{\mathrm{c}} \pm 0.0 \mathrm{ppm}$ \\
Cadmium & $0.0^{\mathrm{c}} \pm 0.0 \mathrm{ppm}$ \\
Chromium & $0.0^{c} \pm 0.0 \mathrm{ppm}$ \\
Manganese & $11.8^{ \pm} \pm 0.1 \mathrm{ppm}$ \\
\hline
\end{tabular}

Values represent means \pm standard deviation.

This assay was done in triplicate $(p<0.05)$.

Table $6 \mathrm{IC}_{50}$ value of DPEA on the tested cell lines

\begin{tabular}{ll}
\hline Cell Line & IC $_{50}$ Value of DPEA \\
MCF-7 & $4.72 \pm 0.52 \mu \mathrm{g} / \mathrm{mL}$ \\
HeLa & NA \\
Hep G2 & NA \\
Glioma & NA \\
MDA-MB-23I & NA \\
L929 & $18.12 \pm 3.46 \mu \mathrm{g} / \mathrm{mL}$
\end{tabular}

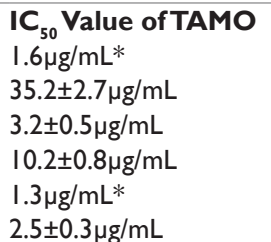

Key: *Indicate for manual calculation.

Saponins are chemical compounds found in particular abundance in various plant species and can be further divided into three major classes which are triterpene glycosides, steroid glycosides and steroid alkaloid glycosides. Saponin has the antioxidant effect, ${ }^{22}$ antiglycation, ${ }^{22,23}$ anti-inflammatory, ${ }^{24}$ surfactant activity due to amphipathic nature, ${ }^{25}$ complexation with cholesterol and causes hemolysis in erythrocyte on iv, enhance proteins penetration through membranes and augment the cytotoxicity of targeted immunotoxins directed against human cancer cell. ${ }^{26}$ Researchers also in line with the present finding where DP had shown to have anticancer and free radical scavenging potency by means of anticancer activity on cell proliferation inhibition and inducing apoptosis of breast cancer cell lines T47D and MCF-7. ${ }^{21,27,28}$

The presence of flavonoids in DP justifies a wide range of possible biological and pharmacological activities. In vitro studies shown that flavonoids been reported to exhibit anti-allergic, ${ }^{29}$ anti- 
inflammatory, ${ }^{29,30}$ antioxidant, ${ }^{30}$ antibacterial, ${ }^{31}$ antifungal and antiviral, ${ }^{31}$ anticancer ${ }^{32}$ and antidiarrheal activities. ${ }^{33}$ Though there is ongoing research into the potential health benefits of individual flavonoids, neither the Food and Drug Administration (FDA) nor the European Food Safety Authority (EFSA) has approved any health claim for flavonoids or approved any flavonoids as pharmaceutical drugs. Study from Marvibaigi and coworkers ${ }^{4}$ pointed out that mistletoe contains different types of biological active compounds including flavonoid. ${ }^{4}$

Alkaloids appear to be active metabolites but their usefulness to plants remains obscure. An alkaloid is a nitrogen-contained organic compound. Medicinal use of alkaloid-contained plant had a long history for instance at 19th century, morphine from Papaver somniferum immediately found application in clinical practice. The presence of alkaloids in DP might indicate that it had the properties of psychoactive substances. Many synthetic and semisynthetic drugs are structural modifications of alkaloids, which were designed to enhance or change the primary effect of drug and reduce unwanted side effects, for instance, naloxone, a derivative from the baine in $P$. somniferum. ${ }^{34}$

According to Fitrilia et al. ${ }^{20}$ DPEA extract from host clove found out to be rich in tannins, flavonoids and triterpenoids but absent of alkaloids and saponins. However, present study shows that alkaloid and saponin were present. The difference in the phytochemical analysis obtained might be due to the different host plant and the choice of the solvent used in maceration extractions.

DPEA had been evaluated through GC-MS to characterize the phytochemical compounds that have been present earlier. It is a good tool to identify constituents of volatile matter, long chain, branched chain hydrocarbons, alcohols, acids and ester. ${ }^{35}$ The identification of the compound was based on the peak area, retention time and molecular formula. As mention earlier, only the most highly abundance compounds detected (highest peak area) will be discuss, including acetoacetic acid, citramalic acid, ethylene glycol monoacetate, ndecanoic acid, palmitic acid, linolenic acid and beta-sitosterin.

Butanoic acid, 2,2-dimethyl-3-oxo-, methyl ester or commonly known as acetoacetic acid, 2,2-dimethyl-, methyl ester (NIST, 2011) is an organic compound with beta-ketone acid group. The compound was stable and used in industrial scale as precursors to dyes. ${ }^{36}$ The restricted ketogenic diet which is high fat, moderate protein, low carbohydrate diet was used as cancer treatment. The restriction refer to the number of calories is limited and the amount of carbohydrate is extremely low. Such diet leads to vital changes in the ways cells in the body are nourished. Healthy cells can use glucose or ketone bodies as their primary energy source. The primary types of ketones that are used as an energy source are acetoacetic acid and beta-hydroxybutyric acid. The emphasize point is that cancer cells are unable to use ketones for their energy source because they rely on glucose and glutamine for metabolism. When a person adopt ketogenic diet, a phenomenon where reduced level of glucose in the blood and elevated levels of ketone bodies, causing cancer cells to have no access to glucose and rapidly die (denied their primary energy source and starved) while all healthy cells in the body nourished by ketones. ${ }^{37}$

Butanedioic acid, 2-hydroxy-2-methyl-, (S)- or commonly known as citramalic acid, plays a role of donating hydrogen atom to acceptor It was commonly found in algae, human and plant metabolites. It is also contribute to the functional parent succinic acid.

1,2-Ethanediol, monoacetate or with common name ethylene glycol, monoacetate was suggested compound in the GC-MS experiment. Through the literature search, poly (ethylene glycol) multiblock copolymer as a carrier of anticancer drug doxorubicin. At the most time, poly(ethylene glycol) frequently used hydrophilic polymer for protein modification. It has been found that "pegylated" proteins like enzymes or antibodies, etc. are more resistant to proteolytic degradation than unmodified ones. They also exhibit much longer circulating times in blood and lower immunogenicity. ${ }^{38}$ Tremendous efforts had been developed for site-specific drug delivery, thereby optimal drug action is necessary to deliver the drug to targeted site in most efficient way. Study from Kim et al. ${ }^{39}$ showed that methoxy poly(ethylene glycol) when pair with poly( $\varepsilon$-caprolactone), MePEG/ PCL could be a novel anticancer drug carriers with low toxicity in male mice. The compound MePEG/PCL was recommended by researchers Kim et al. ${ }^{39}$ for the ease of taxol delivery as taxol exhibit high lipophilic characteristics while with the incorporation of the compound, drug can be suspended in water. ${ }^{39}$

Decanoic acid is a fatty acid, forming a salt or ester with a drug will increase its lipophilicity and its affinity for fatty tissue. Since distribution of a drug from fatty tissue is usually slow, one may develop depot injection by using its decanoate form. Decanoate ester prodrugs of various pharmaceuticals are available. Some examples of drugs available as a decanoate ester include nandrolone, fluphenazine, bromperidol, and haloperidol. Decanoic acid may mimic the mitochondrial proliferation associated with the ketogenic diet and that this may occur via PPAR $\gamma$ receptor agonism and its target genes involved in mitochondrial biogenesis. ${ }^{41}$ Decanoic acid exhibited antiseizure and anticonvulsant effect to ketogenic diet. ${ }^{41}$ However, it had poor bioavailability as orally ingested medium chain fatty acids would be very rapidly degraded by first-pass metabolism by being taken up in the liver via the portal vein and are quickly metabolized via coenzyme $\mathrm{A}$ intermediates through $\beta$-oxidation and the citric acid cycle to produce carbon dioxide, acetate and ketone bodies. ${ }^{42}$ Palmitic acid or n-Hexadecanoic acid is a common saturated fatty acid found in animals, plants and microorganisms. Palmitic acid was used to produce soaps, cosmetics and release agents. These applications utilize sodium palmitate, which is commonly obtained by saponification of palm oil. It is inexpensive and often used as natural additive to add texture to processed foods. Hydrogenation of palmitic acid yields acetyl alcohol which was used to produce detergents and cosmetics. In terms of pharmacological application, paliperidone palmitate was used in the treatment of schizophrenia. Aside from its antipsychotic usage, palmitic acid also like decanoic acid to use in depot medication particularly haloperidol decanoate. The highlighting part of palmitic acid is that it has been studied as anti-tumor ${ }^{43}$ and anticancer ${ }^{44}$ activities. This compound was suggested by Benoit et al. ${ }^{45}$ to play a role in weight regulation as in vivo study from rats fed a diet of palmitic acid shows suppression of the body natural appetite suppressing signals from leptin and insulin. ${ }^{45}$

Linolenic acid (CLA) or linoleic acid is the common name for 9,12,15- Octadecatrienoic acid, methyl ester, (Z,Z,Z)-. It is a polyunsaturated omega- 6 fatty acid and was categorized into essential fatty acids. This compound was known to aids in the prevention of coronary heart disease, reduces plasma lipoproteins and early aortic atherosclerosis in hypercholesterolemic hamsters, cancer preventive activity, anti-inflammatory, hepatoprotective, ${ }^{46}$ anticarcinogen, restore insulin sensitivity, reduced body fat and antioxidant activity. ${ }^{47}$ Interestingly, CLA had been marketed in the form of dietary supplement for its anticancer benefit and bodybuilding aid.

Beta -sitosterol or 22,23-Dihydrostigmasterol, Stigmast-5-en-3ol or $\beta$-Sitosterin is being studied for its potential to reduce benign prostatic hyperplasia and blood cholesterol level. It is known as the precursor of anabolic steroid boldenone. This compound was found 
to have anticancer, hypocholesterolemic, anti-inflammatory and antipyretic properties. As a whole, DPEA sample was rich in chemical compounds particularly decanoic acid, palmitic acid, linolenic acid and beta-Sitosterol. Zainuddin et al. ${ }^{21}$ proposed that the traditional claimed on the medicinal plant DP might be contributing to the existence of these compounds in DP. The finding of the present research project was in line with the result from Zainuddin et al. ${ }^{21,28}$ where benzoic acid, hexadecanoic acid and linolenic acid were in common. Though the GC-MS analysis derived possibility of 39 compounds of DPEA, the purity of the sample would be concerned but the result obtained still considered as valid as bioactive compounds detected supported by previous research.

The purpose of a toxicity test is to produce data concerning the adverse effect of an agent on the test organisms. The most common type of toxicity test with aquatic animals is the acute mortality test which is usually conducted to obtain information about a median lethal concentration, $\mathrm{C}_{50}$. Brine shrimp lethality assay (BSLA) represents a rapid, inexpensive and simple bioassay for testing plant extract lethality which in most cases correlates reasonably well with cytotoxic and anti-tumour properties. ${ }^{48}$ The data produced by the BSLA presents the percentages of mortality of nauplii that were killed by different concentrations of toxicant after specified length of exposure. Generally, BSLA of the plant extracts were found to be concentration-dependent. According to Meyer et al. ${ }^{49}$ crude plant extract is toxic (active) if it has $\mathrm{LC}_{50}$ value of less than $1000 \mu \mathrm{g} / \mathrm{mL}$ whereas non-toxic (inactive) if it is greater than $1000 \mu \mathrm{g} / \mathrm{mL} . \mathrm{LC}_{50}$ is a standard measure of the toxicity of the surrounding medium that will kill half of the sample population of a specific period through extract exposure. In this study, DPEA extract did not show significant result on $\mathrm{LC}_{50}$ value. $\mathrm{LC}_{50}$ was not being able to calculate since the extract is incapable in causing death of the brine shrimp even at $50 \%$. The finding of the present study was encouraging by previous research where Artanti et al. ${ }^{6}$ found out that both DP methanolic and water extract are relatively safe to be consume as traditional or alternative medicine. The BSLA value obtained was more than $1000 \mu \mathrm{g} / \mathrm{mL} .^{6}$ Following studies using DPEA on cancer cell lines was performed to know if they have anticancer potential. If the extract is found to be not toxic in BSLA but found to be toxic in cancer cell line assay, it could be a good indication that the cytotoxic compounds in the DPEA might have more specificity to cancer cells and hopefully less toxic to normal cells. ${ }^{6}$

The safety of herbal medicines is a global concern and national health authorities have developed mandates to ensure the safe use of herbal medicines. Herbal medicines might subject to potentially hazardous contaminants and residues. Contaminants in herbal medicines are classified into physicochemical contaminants and biological contaminants. Such contamination should be avoided through quality assurance measures such as good agricultural and collection practices (GACP) for medicinal plants and good manufacturing practices (GMP) for herbal medicines. ${ }^{50}$

Due to the variation and inherent complexities of herbal drugs, the WHO standard was strictly followed as reference of heavy metal level. To further understand the elemental composition of DP plant, AAS test was performed in order to protect public health and keep residues and contaminants at levels which are toxicologically acceptable. In the present study, heavy metals detected were below the maximum permissible level suggested by WHO. DPEA had been evaluated through $\mathrm{IC}_{50}$ value, which represents the concentration of compound that is required to inhibit $50 \%$ of cell population in vitro. ${ }^{51}$ National Cancer Institute (NCI) has reported those crude extracts which demonstrate $\mathrm{IC}_{50}$ less than $20 \mu \mathrm{g} / \mathrm{mL}$ is considered to have good cytotoxic activity against cell lines. ${ }^{52}$ In this study, that range value was used as a rough reference point for evaluating the activity of the DPEA extract. The determination of percentage of cell viability was conducted by using MTT assay. Result showed that there was no anti-proliferative activities were acquired from DPEA extract on HeLa, HepG2, Glioma and MD-AMB 231 as the $\mathrm{IC}_{50}$ value was high. In contrast, the DPEA exhibited good anti-proliferative activity towards MCF-7 cells. DPEA extract showed less effect on L929 cell proliferation. On the other hand, tamoxifen, an approved drug by Food and Drug Administration (FDA) was used as positive control to reduce cancer occurrence especially breast cancer. The positive control, tamoxifen exhibited anti-proliferative activity on HeLa cells and normal cells, L929 cells. Growth of some cancer cells may initially be attenuated by tamoxifen but become resistant to continued treatment and the cells can continue to grow. ${ }^{53}$ Undesired side effects have affected healthy L929 cells when given tamoxifen treatment and DPEA treatment. In contrast with the toxicity of tamoxifen, DPEA show less cytotoxicity. The negative control used was DMSO. Using Prism, the $\mathrm{IC}_{50}$ value for MCF-7 and MD-AMB 231 was found out to be too wide to be determined. However, we had performed manual calculation to obtain $\mathrm{IC}_{50}$ value of MCF-7 and MD-AMB 231. For this screening assay, malignant cell lines MCF-7 and L929 cells showed significant anti-proliferative activity. From the previous study, Zainuddin stated that different types of extract could reveal different therapeutic effects towards MCF-7 breast cancer cells. ${ }^{28}$ The present finding in tandem of the previous work where DPEA inhibit MCF-7 cell growth in MTT treatment.

From the literature search, DP was found out to have antiproliferative activity on breast cancer cell line T47D cell proliferation and induce apoptosis using MTS assay. ${ }^{27}$ Another study from Zainuddin $^{21,28}$ performed MBA assay and reported that no $\mathrm{IC}_{50}$ detected in MDCK, L929 and Vero cell lines when tested with several concentrations of the extract. This indicates that the DP extract does not show any severe cytotoxic effect on mammalian normal cells from previous studies. No toxicity on this results of all DP extracts could be a good sign that this plant is relatively non-toxic, thus it is relatively save to be consume for traditional medicine. DPEA extract could be possible candidates with promising potency to be developed as new chemotherapeutic candidate with further study. The search for anticancer property from the leaves of DP is scarcely reported. To understand more on the cytotoxicity effect of DP or the mechanism of DP as potential anticancer candidate was still remained unknown and should be in-depth studied. The active compound present in DPEA need to be isolated and this could lead to the discovery of a novel compound. Understanding functional role and regulation of apoptotic events of DP will provide mechanisms involved in cancer cell proliferation and in combating malignancy.

\section{Conclusion}

In conclusion, the result from the present research could be an encouraging evidence to show that DP plant was relatively safe and non-toxic. The phytochemicals present in DP were alkaloids, tannins, saponins, and flavonoids. Plant extract did not show $50 \%$ mortality of nauplii thus the $\mathrm{LC}_{50}$ of the extract still remain unknown. However, based on the finding of the statistical analysis and mathematical equation, the $\mathrm{LC}_{50}$ can be deducing as more than $1000 \mathrm{ppm}$. Heavy metal content detected in DP passed the maximum permissible level suggested by WHO guidelines. DPEA shows antiproliferative activity on MCF-7 of $\mathrm{IC}_{50} 4.72 \pm 0.52 \mu \mathrm{g} / \mathrm{mL}$ and L929 of $\mathrm{IC}_{50} 18.12 \pm 3.46 \mu \mathrm{g} /$ $\mathrm{mL}$. Chemical compounds especially decanoic acid, palmitic acid, linolenic acid and beta-Sitosterol was suggested to contribute to the medicinal use of DP among community. The finding of the study only 
conclude the safety and toxicity of DP plant subject to the host plant Lansium parasiticum using the methodology described. Chemical composition of DP plant can be varies depending on techniques of extract preparation, season and time of harvesting, commercial producer, stage of growth of the plant, location and species of the host tree.

\section{Acknowledgements}

Authors would like to thank Universiti Sains Malaysia for FRGS funding (203/PPSK/6171150). I also would like to delivery my gratitude to the staffs from Unit Pengurusan Makmal Sains (UPMS) and analytical laboratory for the facilities and technical assistance provided.

\section{Conflicts of interest}

The authors declare that there is no conflict of interests regarding the publication of this paper.

\section{References}

1. Chavan SS, Damale MG, Shamkuwar PB. Traditional medicinal plants for anticancer activity. International Journal of Current Pharmaceutical Research. 213;5(4):50-54.

2. Solowey E, Lichtenstein M, Sallon S, et al. Evaluating medicinal plants for anticancer activity. The Scientific World Journal. 2013;2014:1-12.

3. Gordaliza M. Natural products as leads to anticancer drugs. Clin Transl Oncol. 2007;9(12):767-776.

4. Marvibaigi M, Supriyanto E, Amini N, et al. Preclinical and clinical effects of mistletoe against breast cancer. Biomed Res Int. 2014;2014:785479.

5. Artanti N, Maarifa Y, Hanafi M. Isolation and identification of active antioxidant compound from star fruit (Averrhoa carambola) mistletoe (Dendrophthoe pentandra (L.) miq.) ethanol extract. Journal of Applied Sciences. 2006;6(8):1659-1663.

6. Artanti N, Firmansyah T, Darmawan A. Bioactivities Evaluation of Indonesian Mistletoes (Dendrophthoe pentandra (L.) Miq.) Leaves Extracts. Journal of Applied Pharmaceutical Science. 2012;2(1):24-27.

7. Sofowara AE. Research on Medicinal plants and traditional medicine in Africa. J Altern Complement Med. 1993;2(3):365-372.

8. Harborne JB. Phytochemical methods a guide to modern techniques of plant analysis. Springer, Netherlands. 1998.

9. Kodithala S, Yoganandam GP, Kiranmai M. Pharmacognostical, phytochemical and anticancer studies of Dendrophthoe falcata (lf) ettingsh.(Loranthaceae) growing on the host plant Azadirachta indica (Meliaceae). Int J Pharm Bio Sci. 2013;4(2):1010-1018.

10. Jaiswal D, Kumar Rai P, Kumar A, et al. Effect of Moringa oleifera Lam. leaves aqueous extract therapy on hyperglycemic rats. $J$ Ethnopharmacol. 2009;123(3):392-396.

11. Kavanaugh CJ, Trumbo PR, Ellwood KC. The US Food and Drug Administration's evidence-based review for qualified health claims: tomatoes, lycopene, and cancer. J Natl Cancer Inst. 2007;99(14):10741085 .

12. Kim JY, Kwon O. Garlic intake and cancer risk: an analysis using the Food and Drug Administration's evidence-based review system for the scientific evaluation of health claims. Am J Clin Nutr. 2009;89(1):257264.

13. http://www.fruitsandveggiesmorematters.org/what-are-phytochemicals

14. Hassanpour S, MaheriSis N, Eshratkhah B. Plants and secondary metabolites (Tannins): A review. International Journal of Forest, Soil and Erosion. 2011;1(1):47-53.
15. Ashok PK, Upadhyaya K. Tannins are astringent. Journal of Pharmacognosy and Phytochemistry. 2012;1(3):45-50.

16. Serrano J, Puupponen-Pimiä R, Dauer A, et al. Tannins: Current knowledge of food sources, intake, bioavailability and biological effects. Mol Nutr Food Res. 2009;53(S2):S310-S329.

17. Kris-Etherton PM, Hecker KD, Bonanome A, et al. Bioactive compounds in foods: their role in the prevention of cardiovascular disease and cancer. Am J Med. 2002;113(9):71-88.

18. Nagao T, Hase T, Tokimitsu I. A green tea extract high in catechins reduces body fat and cardiovascular risks in humans. Obesity. 2007;15(6):1473-1483.

19. Strick R, Strissel PL, Borgers S, et al. Dietary bioflavonoids induce cleavage in the MLL gene and may contribute to infant leukemia. Proc Natl Acad Sci U S A. 2000;97(9):4790-4795.

20. Fitrilia T, Bintang M, Safithri M. Phytochemical screening and antioxidant activity of clove mistletoe leaf extracts (Dendrophthoe pentandra (L.) Miq). Journal of Pharmacy. 2015;5(8):13-18.

21. Zainuddin NASN, Sul'ain MD. Phytochemical Analysis, Toxicity and Cytotoxicity Evaluation of Dendrophthoe Pentandra Leaves Extracts. International Journal of Applied Biology and Pharmaceutical Technology. 2015b;6(1):108-116.

22. Rodrigues HG, Diniz YS, Faine LA, et al. Antioxidant effect of saponin: potential action of a soybean flavonoid on glucose tolerance and risk factors for atherosclerosis. Int J Food Sci Nutr. 2005;56(2):79-85.

23. Xi M, Hai C, Tang H, et al. Antioxidant and antiglycation properties of total saponins extracted from traditional Chinese medicine used to treat diabetes mellitus. Phytother Res. 2008;22(2):228-237.

24. Sur P, Chaudhuri T, Vedasiromoni JR, et al. Antiinflammatory and antioxidant property of saponins of tea [Camellia sinensis (L) O. Kuntze] root extract. Phytother Res. 2001;15(2):174-176.

25. Chen WJ, Hsiao LC, Chen KKY. Metal desorption from copper (II)/ nickel (II)-spiked kaolin as a soil component using plant-derived saponin biosurfactant. Process Biochemistry. 2008;43(5):488-498.

26. Batista-Duharte A, Lindblad EB, Oviedo-Orta E. Progress in understanding adjuvant immunotoxicity mechanisms. Toxicol Lett. 2011;203(2):97-105.

27. Wahyu Widowati, Tjandrawati Mozef, Chandra Risdian, et al. Anticancer and free radical scavenging potency of Catharanthus roseus, Dendrophthoe petandra, Piper betle and Curcuma mangga extracts in breast cancer cell lines. Oxid Antioxid Med Sci. 2013;2(2):137-142.

28. Zainuddin NASN, Sul'ain MD.) Antiproliferative Effect of Dendrophthoe pentandra extracts towards human breast adenocarcinoma cells (MCF7). Jurnal Teknologi. 2015a;77(2).

29. Yamamoto Y, Gaynor RB. Therapeutic potential of inhibition of the NF$\mathrm{\kappa B}$ pathway in the treatment of inflammation and cancer. $J$ Clin Invest. 2001;107(2):135-142.

30. Cazarolli LH, Zanatta L, Alberton EH, et al. Flavonoids: Prospective drug candidates. Mini Rev Med Chem. 2008;8(13):1429-1440.

31. Cushnie TP, Lamb AJ. Antimicrobial activity of flavonoids. Int $J$ Antimicrob Agents. 2005;26(5):343-56.

32. Ruela de Sousa RR, Queiroz KCS, Souza ACS, et al. Phosphoprotein levels, MAPK activities and NFKB expression are affected by fisetin. Journal of Enzyme Inhibition and Medicinal Chemistry. 2008;22(4):439444.

33. Schuier M, Sies H, Illek B, et al. Cocoa-related flavonoids inhibit CFTRmediated chloride transport across T84 human colon epithelia. J Nutr. 2005;135(10):2320-2325.

34. Hesse M. Alkaloids: nature's curse or blessing? Angewandte Chemie. 2002;42(40):4852-4854 
35. Sermakkani M, Thangapandian V. GC-MS analysis of Cassia italica leaf methanol extract. Asian Journal of Pharmaceutical and Clinical Research. 2012;5(2):90-94.

36. Pelc H, Elvers B, Hawkins S. Wiley-VCH Verlag GmbH \& Co. Germany. 2005.

37. Thomas PJ. We lost the war on cancer - Review of alternative cancer therapies. Sophia Media. 2014.

38. Pechar M, Ulbrich K, Šubr V, et al. Poly(ethylene glycol) multiblock copolymer as a carrier of anti-cancer drug doxorubicin. Bioconjugate Chemistry. 2000;11(2):131-139.

39. Kim SY, Lee YM. Taxol-loaded block copolymer nanospheres composed of methoxy poly (ethylene glycol) and poly ( $\varepsilon$-caprolactone) as novel anticancer drug carriers. Biomaterials. 2001;22(13):1697-1704.

40. Hughes SD, Kanabus M, Anderson G, et al. The ketogenic diet component decanoic acid increases mitochondrial citrate synthase and complex I activity in neuronal cells. J Neurochem. 2014;129(3):426433.

41. Chang P, Augustin K, Boddum K, et al. Seizure control by decanoic acid through direct AMPA receptor inhibition. Brain. 2014;139(Pt 2):431443.

42. Chang P, Terbach N, Plant N, et al. Seizure control by ketogenic dietassociated medium chain fatty acids. Neuropharmacology. 2013;69:105114

43. Harada H, Yamashita U, Kurihara H, et al. Antitumor activity of palmitic acid found as a selective cytotoxic substance in a marine red alga. Anticancer Res. 2001;22(5):2587-2590

44. Yoo YC, Shin BH, Hong JH, et al. Isolation of fatty acids with anticancer activity from Protaetia brevitarsis Larva. Archives of Pharmacal Research. 2007;30(3):361-365.
45. Benoit SC, Kemp CJ, Elias CF, et al. Palmitic acid mediates hypothalamic insulin resistance by altering $\mathrm{PKC}-\theta$ subcellular localization in rodents. J Clin Invest. 2009;119(9):2577-2589.

46. Makni M, Fetoui H, Gargouri NK, et al. Hypolipidemic and hepatoprotective effects of flax and pumpkin seed mixture rich in $\omega-3$ and $\omega-6$ fatty acids in hypercholesterolemic rats. Food Chem Toxicol. 2008;46(12):3714-3720

47. Peyrat-Maillard M, Cuvelier M, Berset C. Antioxidant activity of phenolic compounds in 2, 2'-azobis (2-amidinopropane) dihydrochloride (AAPH)-induced oxidation: Synergistic and antagonistic effects. Journal of the American Oil Chemists'Society. 2003;80(10):1007-1012.

48. Pelka M, Danzl C, Distler W, et al. A new screening test for toxicity testing of dental materials. J Dent. 2000;28(5):341-345.

49. Meyer BN, Ferrigni NR, Putnam JE, et al. Brine shrimp: A convenient general bioassay for active plant constituents. Plant Medm. 1982;45(5):31-34

50. WHO. WHO guidelines for assessing quality of herbal medicines with reference to contaminants and residues. Geneva: World Health Organization, Swizerland. 2007.

51. Zazali KE, Abdullah H, Noor Jamil N. Methanol extract of Oroxylum indicum leaves induces G1/S cell cycle arrest in HeLa cells via p53mediated pathway. International Journal of Medicinal Plant Research. 2006;2(7):225-237.

52. Mutee AF, Salhimi SM, Ghazali FC, et al. Apoptosis induced in human breast cancer cell line by Acanthaster planci starfish extract compared to tamoxifen. African Journal of Pharmacy and Pharmacology. 2002;6(3): $129-134$.

53. Clemons M, Danson S, Howell A. Tamoxifen ('Nolvadex'): A review. Journal of Clinical Oncology. 2002;28(4):165-180. 